\title{
TEMPERATURAS E REGULADOR DE CRESCIMENTO NA GERMINAÇÃO DE SEMENTES DE ALFACE
}

Cleisson Dener da Silva ${ }^{*}$, Andréia Márcia Santos de Souza David ${ }^{2}$, Marcela de Castro Soares $^{3}$, Edileuza dos Reis Souza Conceição ${ }^{1}$, Eliene Almeida Paraizo ${ }^{4}$, Rafael Rogério Pereira da Silva ${ }^{1}$, Danúbia Aparecida Costa Nobre ${ }^{5}$

\footnotetext{
${ }_{1}^{1}$ Mestrando em Produção Vegetal no Semiárido, Universidade Estadual de Montes Claros (Unimontes), Janaúba, MG. *E-mail do autor correspondente: denercleisson5@hotmail.com

${ }^{2}$ Docente do curso de Agronomia, Universidade Estadual de Montes Claros (Unimontes), Janaúba, MG.

${ }^{3}$ Engenheira Agrônoma, Universidade Estadual de Montes Claros (Unimontes), Janaúba, MG.

${ }^{4}$ Doutoranda em Produção Vegetal no Semiárido, Universidade Estadual de Montes Claros (Unimontes), Janaúba, MG.

${ }^{5}$ Docente do curso de Agronomia, Universidade Federal dos Vales do Jequitinhonha e Mucuri (UFVJM), Campus JK, Diamantina, MG.
}

Recebido: 22/02/2020; Aceito: 23/07/2020

RESUMO: A alface apresenta sensibilidade às variações de temperatura durante a germinação, sendo afetada negativamente por altas temperaturas. Deste modo, métodos capazes de minimizar tais efeitos, se revestem de grande importância para promover germinação satisfatória. Assim, objetivou-se com o presente estudo avaliar a utilização do etefon (precursor do etileno) na germinação de sementes de alface sob diferentes condições de temperatura. $\mathrm{O}$ delineamento experimental foi o inteiramente casualizado em esquema fatorial $2 \times 6$, sendo duas temperaturas $\left(20\right.$ e $\left.30^{\circ} \mathrm{C}\right)$ e seis concentrações de etefon $(0,200,400,600$, 800 e 1000 ppm), com quatro repetições. Avaliaram-se a germinação, protrusão radicular, primeira contagem da germinação e índice de velocidade de germinação. O etefon maximizou a germinação e velocidade de germinação de sementes de alface expostas à temperatura de $30^{\circ} \mathrm{C}$, enquanto na temperatura de $20^{\circ} \mathrm{C}$ ocorreram decréscimos. Incrementos também foram verificados no percentual de protrusão radicular para as sementes expostas a $30^{\circ} \mathrm{C}$. Em todas as concentrações estudadas, a temperatura de $20^{\circ} \mathrm{C}$ proporcionou maior percentual e velocidade de germinação. Concentrações entre 726 e 786 ppm proporcionaram melhores respostas no desempenho germinativo de sementes submetidas a $30^{\circ} \mathrm{C}$, ao passo que em temperatura de $20^{\circ} \mathrm{C}$ o etefon promoveu efeito negativo.

Palavras-chave: Condição térmica. Fitorregulador. Lactuca sativa L.

\section{TEMPERATURES AND GROWTH REGULATOR IN THE GERMINATION OF LETTUCE SEEDS}

\begin{abstract}
Lettuce is sensitive to temperature variations during germination, being negatively affected by high temperatures. Thus, methods capable of minimizing such effects are of great importance to promote satisfactory germination. Thus, the objective of this study was to evaluate the use of etefon (ethylene precursor) in the germination of lettuce seeds under different temperature conditions. The experimental design was completely randomized
\end{abstract}


in a $2 \times 6$ factorial scheme, with two temperatures $\left(20\right.$ and $\left.30^{\circ} \mathrm{C}\right)$ and six concentrations of etefon $(0,200,400,600,800$ and $1000 \mathrm{ppm})$, with four replications. Germination, root protrusion, first germination count and germination speed index were evaluated. Etefon maximized the germination and germination speed of lettuce seeds exposed to a temperature of $30^{\circ} \mathrm{C}$, while at a temperature of $20^{\circ} \mathrm{C}$ there were decreases. Increments were also seen in the percentage of root protrusion for seeds exposed to $30^{\circ} \mathrm{C}$. In all studied concentrations, the temperature of $20^{\circ} \mathrm{C}$ provided a higher percentage and speed of germination. Concentrations between 726 and $786 \mathrm{ppm}$ provided better responses in the germinative performance of seeds submitted to $30^{\circ} \mathrm{C}$, while at $20^{\circ} \mathrm{C}$ the etphon promoted a negative effect.

Key words: Thermal condition. Phytoregulator. Lactuca sativa L.

\section{INTRODUÇÃO}

A alface (Lactuca sativa L.) é a hortaliça folhosa de maior importância no mercado mundial e nacional sendo, no Brasil, a mais popular dentre aquelas em que as folhas são consumidas cruas e ainda frescas (SALA; COSTA, 2012). Além disso, é cultivada o ano todo, em diferentes regiões, o que facilita sua distribuição.

Contudo, o sucesso da cultura é dependente, dentre outros fatores, do estabelecimento de plântulas em campo, apresentando relação direta no processo germinativo das sementes. A propagação da alface se dá por meio de sementes, as quais são reconhecidamente problemáticas em termos de qualidade fisiológica, revelando alta sensibilidade às condições de ambiente, frequentemente inadequadas para a ocorrência de rápida emergência e desenvolvimento inicial da planta (ALMEIDA, 2016).

Normalmente, a produção é prejudicada em algumas regiões do Brasil devido à ocorrência de temperaturas elevadas, sendo um dos problemas principais o fato da temperatura alta interferir negativamente no processo de germinação das sementes.

A temperatura ideal para a germinação de sementes de alface situa-se em torno de $20^{\circ} \mathrm{C}$, sendo um fator que incide influência determinante no processo germinativo, e a maioria das cultivares não germinam em temperaturas superiores a $30^{\circ} \mathrm{C}$, isso porque a origem da alface é de regiões de clima temperado, sul da Europa e Ásia Ocidental (NASCIMENTO; PEREIRA, 2007).

A exposição das sementes a temperaturas elevadas durante o processo de embebição pode acarretar fenômenos como a termoinibição e a termodormência, correspondendo respectivamente à inibição temporária e completa da germinação, em decorrência do enrijecimento do endosperma o qual restringe a protrusão da radícula (NASCIMENTO; CRODA; LOPES, 2012).

Deste modo, quando as sementes têm sua germinação limitada pelo endosperma, é essencial que ocorra o enfraquecimento desse tecido para que haja a emissão da radícula, cuja função é exercida por enzimas como a endo- $\beta$-mananase (SILVA et al., 2004). Tendo em vista que a parede celular do endosperma é composta principalmente por polímeros de 
galactomananos, tal enzima desempenha importante papel (IGLESIAS-FERNÁNDEZ et al., 2010), culminando no avanço do processo germinativo.

Segundo Nascimento (2002), a regulação de enzimas endo- $\beta$-mananase responsáveis pela "digestão" da parede celular do endosperma podem estar diretamente ligadas à produção do hormônio etileno, que atua no enfraquecimento do endosperma da semente. Estes processos podem favorecer a emissão da radícula e, consequentemente, a germinação das sementes de alface sob altas temperaturas.

Ademais, Iglesias-Fernández e Matilla (2010) apontam a ação do etileno nas sementes, especialmente em condições de estresse, o qual pode estar envolvido em respostas hormonais, interagindo com a giberelina e/ou inibindo a atividade do ácido abscísico, estimulando a germinação. No entanto, as pesquisas sobre o real mecanismo de atuação do etileno nas sementes não são conclusivas.

Portanto, torna-se necessária a realização de estudos referentes a alternativas que viabilizem e adequem o cultivo de alface às diferentes condições tropicais encontradas no país. Assim, objetivou-se com o presente trabalho avaliar o efeito de concentrações de etefon na germinação e vigor de sementes de alface sob diferentes temperaturas.

\section{MATERIAL E MÉTODOS}

O experimento foi realizado no Laboratório de Análise de Sementes do Departamento de Ciências Agrárias da Universidade Estadual de Montes Claros (Unimontes), campus Janaúba-MG, no período de maio a junho de 2019. Foram utilizadas sementes de alface da cultivar Grand Rapids TBR, categoria não certificadas de segunda geração (S2), com germinação de $85 \%$.

O delineamento experimental utilizado foi o inteiramente casualizado, em esquema fatorial $2 \times 6$, sendo duas temperaturas $\left(20\right.$ e $\left.30^{\circ} \mathrm{C}\right)$ e seis concentrações de etefon $(0,200$, 400, 600, 800 e 1000 ppm), com quatro repetições de 50 sementes por tratamento, totalizando 48 unidades experimentais. Para a concentração de 0 ppm (tratamento controle) utilizou-se apenas água destilada.

As concentrações foram definidas com base na pesquisa desenvolvida por Villela (2009). O preparo das soluções foi realizado utilizando-se o produto comercial Ethrel ${ }^{\circledR}$, constituído pelo ingrediente ativo ácido 2-cloroetilfosfônico (etefon 240 g.L. $\mathrm{L}^{-1}$ ) e 865 g.L.-1 de ingredientes inertes, o qual foi diluído nas proporções de 0,$8 ; 1,6 ; 2,5 ; 3,3$ e 4,2 mL por litro de água, obtendo assim, as respectivas concentrações.

Inicialmente foi determinado o teor de água das sementes pelo método da estufa a $105 \pm$ $3^{\circ} \mathrm{C}$, durante 24 horas, conforme Brasil (2009), utilizando-se quatro repetições de 100 sementes, com os resultados expressos em porcentagem.

Para o teste de germinação, as sementes foram semeadas sobre papel germitest $^{\circledR}$, umedecido com as soluções de etefon em volume equivalente a 2,5 vezes o peso seco e disposto em caixas plásticas do tipo gerbox $(11,5 \times 11,5 \times 3,5 \mathrm{~cm})$. As caixas foram mantidas em germinadores digitais regulados de acordo com as temperaturas descritas para os 
tratamentos $\left(20\right.$ e $30^{\circ} \mathrm{C}$ constantes), sendo as avaliações realizadas no sétimo dia após a semeadura, que consistiu na contagem do número de plântulas normais, com os resultados expressos em porcentagem. Foram consideradas normais as plântulas que apresentaram estruturas essenciais (sistema radicular e parte aérea) completas, desenvolvidas, proporcionais e sadias (BRASIL, 2009).

Após 48 horas da instalação do teste de germinação, período suficiente para as sementes atingirem a fase III de embebição (RODRIGUES et al., 2012), foi avaliada a protrusão radicular, sendo um teste de vigor fundamentado no princípio de que sementes com maior vigor emitem a raiz primária mais rapidamente que as menos vigorosas (PEREIRA et al., 2012). Para tanto, foram computadas as sementes que apresentaram emissão de radícula, com pelo menos dois milímetros de comprimento visível, com os resultados expressos em porcentagem.

Em conjunto com o teste de germinação foi determinada a primeira contagem de germinação na qual consistiu do registro do número de plântulas normais obtidas no quarto dia após a semeadura, com os resultados expressos em porcentagem (BRASIL, 2009).

O índice de velocidade de germinação (IVG) constituiu em avaliações diárias, do número de sementes que apresentaram protrusão de radícula até a formação de uma plântula normal. Ao final do teste, com os dados obtidos das avaliações diárias, foi calculado o IVG, empregando-se a fórmula proposta por Maguire (1962).

As variáveis estudadas foram analisadas através do programa Sisvar (FERREIRA, 2011). Os resultados foram submetidos à análise de variância, as médias resultantes das temperaturas comparadas pelo teste de Tukey a 5\% de probabilidade e as médias provenientes das concentrações de etefon foram submetidas à análise de regressão, com as estimativas dos parâmetros avaliadas pelo teste "t" em nível de 5\% de significância.

\section{RESULTADOS E DISCUSSÃO}

A determinação do teor de água demonstrou que as sementes de alface apresentaram 6,9\% de umidade, encontrando-se dentro dos limites estabelecidos para sementes ortodoxas (COSTA, 2012), indicando a possibilidade de prosseguimento da pesquisa por meio da aplicação dos testes com a obtenção de resultados consistentes.

A germinação foi influenciada significativamente pelas temperaturas e concentrações de etefon, indicando interação significativa $(\mathrm{P}<0,05)$ entre os fatores estudados. Observa-se que sementes submetidas à temperatura de $20^{\circ} \mathrm{C}$ sofreram reduções na germinação em função do aumento da concentração de etefon (Figura 1). O tratamento controle (0 ppm) possibilitou maior porcentagem de germinação (94\%), enquanto que na maior concentração (1000 ppm) houve decréscimo, correspondendo a uma redução de 14\%, contudo, manteve o percentual mínimo exigido para sementes certificadas de alface (80\%), estabelecido pelo Ministério da Agricultura, Pecuária e Abastecimento (BRASIL, 2012).

Em contrapartida, sementes expostas à temperatura de $30^{\circ} \mathrm{C}$ tiverem aumento gradativo na germinação até a concentração de 786 ppm, onde verificou-se o maior percentual 
germinativo (55\%), havendo em seguida, uma redução de 1\% (Figura 1). Esses resultados podem ser atribuídos à ação do etileno, o qual atua diretamente no enfraquecimento do endosperma da semente, podendo estar ligado à ativação de enzimas ligadas à "digestão" da parede celular do endosperma, facilitando a emissão radicular e, portanto, a germinação das sementes expostas a temperaturas mais elevadas (NASCIMENTO; CANTLIFFE, 2002).

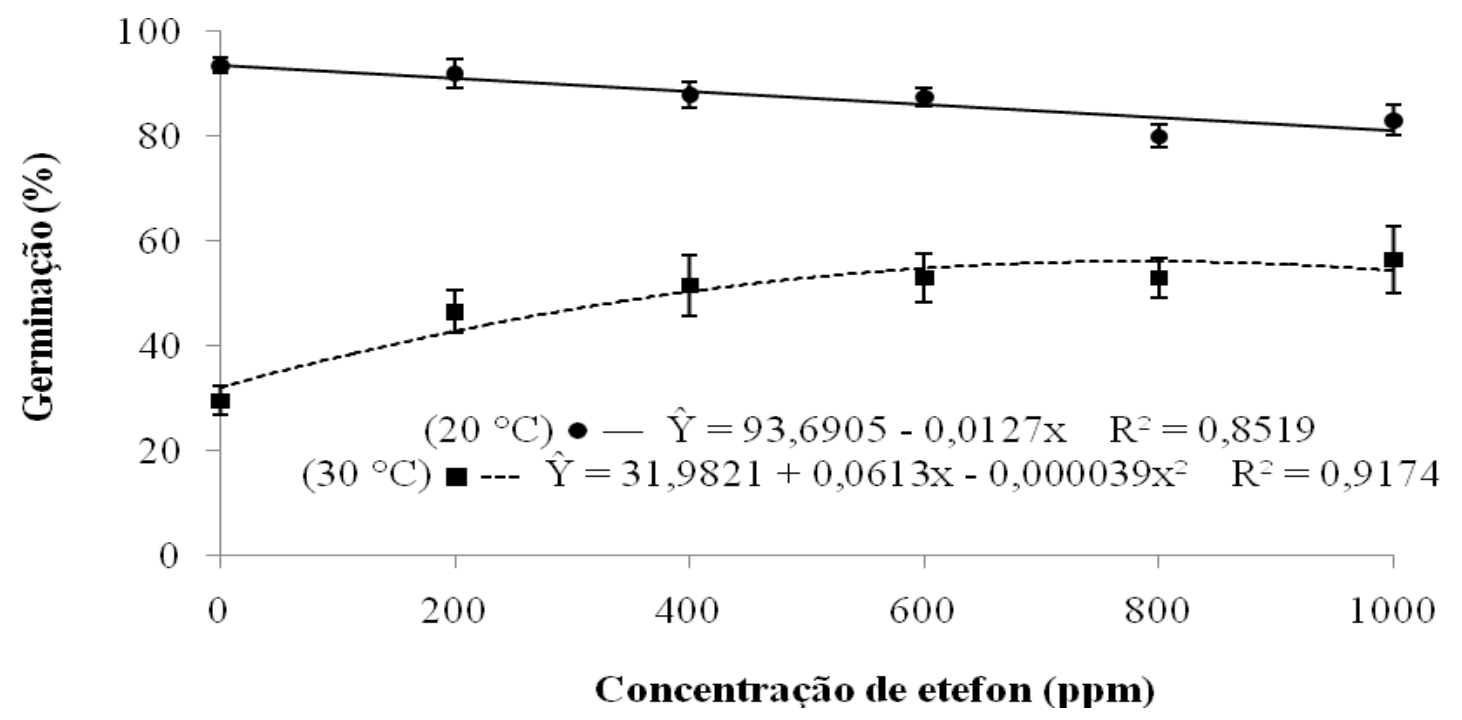

Figura 1. Germinação de sementes de alface submetidas a diferentes temperaturas em função da concentração de etefon. Germination of lettuce seeds submitted to different temperatures as a function of ethephon concentration.

Fonte: Autoria própria. Own authorship.

No entanto, vale ressaltar que apesar do etefon não ter promovido germinação semelhante à obtida na temperatura ideal $\left(20^{\circ} \mathrm{C}\right)$, sua utilização maximizou a germinação das sementes, promovendo efeito atenuador sob a temperatura de $30^{\circ} \mathrm{C}$, cuja concentração de 786 ppm possibilitou um incremento de $72 \%$ em relação ao tratamento controle (Figura 1).

Houve interação significativa $(\mathrm{P}<0,05)$ entre as temperaturas e as concentrações de etileno para a variável protrusão radicular após 48 horas de montagem do teste (Figura 2). No entanto, não foi constatada diferença estatística entre as diferentes concentrações na temperatura recomendada para a cultura $\left(20^{\circ} \mathrm{C}\right)$. Já em condição de temperatura elevada $\left(30^{\circ} \mathrm{C}\right)$, o etefon promoveu efeito sobre a protrusão radicular, cujo tratamento controle resultou em apenas 25\%, corroborando com a análise de Nascimento, Croda e Lopes (2012), em que sementes de alface expostas a altas temperaturas durante a embebição, podem apresentar inibição no processo germinativo, em decorrência do endurecimento do endosperma, que restringe a emissão da radícula.

Contudo, com a utilização do etefon observou-se aumento nos percentuais até a concentração de 726 ppm, onde foi verificado o máximo percentual (80\%). Nascimento e Cantliffe (2002) ressaltam que o etileno pode minimizar o efeito inibitório de temperaturas elevadas no processo germinativo de sementes de alface, por meio da ativação de enzimas da parede celular que atuam na digestão do endosperma, promovendo então, a protrusão da radícula. 


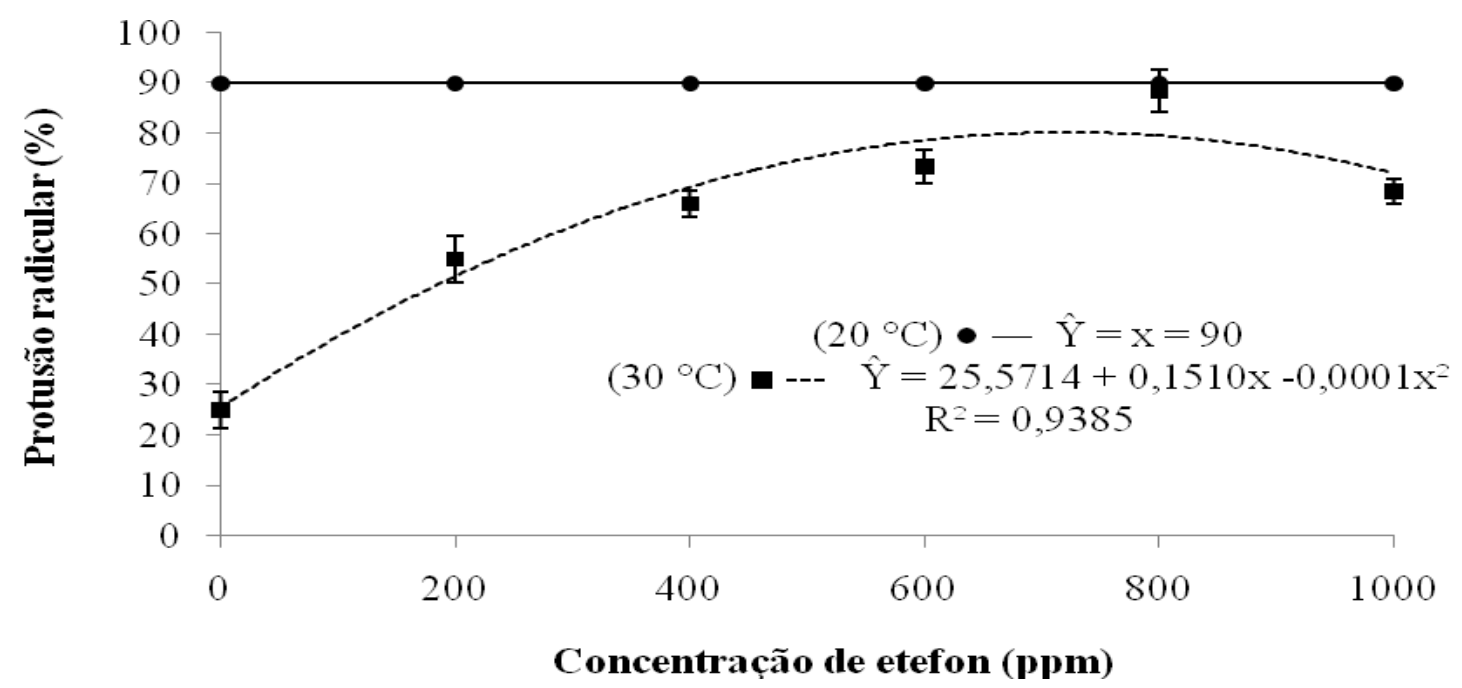

Figura 2. Protrusão radicular de sementes de alface após 48 horas submetidas a diferentes temperaturas em função da concentração de etefon. Root protrusion of lettuce seeds after 48 hours submitted to different temperatures as a function of ethephon concentration.

Fonte: Autoria própria. Own authorship.

Posteriormente, ocorreu uma redução de $9 \%$ até a concentração de 1000 ppm (Figura 2), indicando a necessidade da determinação de uma dosagem adequada, haja visto que doses exageradas tendem a promover efeito danoso tanto na germinação quanto nas demais características testadas. Neste sentido, Faria (2017) destaca que existem limites ideais de concentração para que o hormônio apresente eficácia, de modo que concentrações inferiores não promovem respostas fisiológicas e concentrações superiores proporcionam ação inibitória, conforme observado no presente estudo.

A primeira contagem de germinação foi influenciada significativamente $(\mathrm{P}<0,05)$ pela interação entre as concentrações de etefon e as temperaturas em estudo. Analisando o comportamento das concentrações na temperatura de $20^{\circ} \mathrm{C}$, observou-se que os resultados se ajustaram em uma equação de regressão de comportamento linear, com redução nos porcentuais de plântulas normais na primeira contagem proporcional ao aumento da concentração de etefon (Figura 3). Assim, a concentração de 1000 ppm promoveu uma redução de $16 \%$, em relação ao tratamento controle $(0 \mathrm{ppm})$, indicando provável efeito inibitório do etefon em concentrações mais elevadas, conforme relatado por Faria (2017).

Já para a temperatura de $30^{\circ} \mathrm{C}$, os resultados de primeira contagem se ajustaram a um modelo de regressão de comportamento quadrático, no qual os valores percentuais intensificaram até a concentração de $781 \mathrm{ppm}$, tendo alcançado o maior percentual de germinação na primeira contagem (57\%), o que correspondeu a um incremento de $90 \%$ (Figura 3). Esses resultados demonstram aumento no vigor em sementes de alface com o emprego do etefon sob temperatura elevada, uma vez que o teste de primeira contagem da germinação é baseado no pressuposto de que as sementes mais vigorosas conseguem germinar mais depressa (ABUD et al., 2013). 


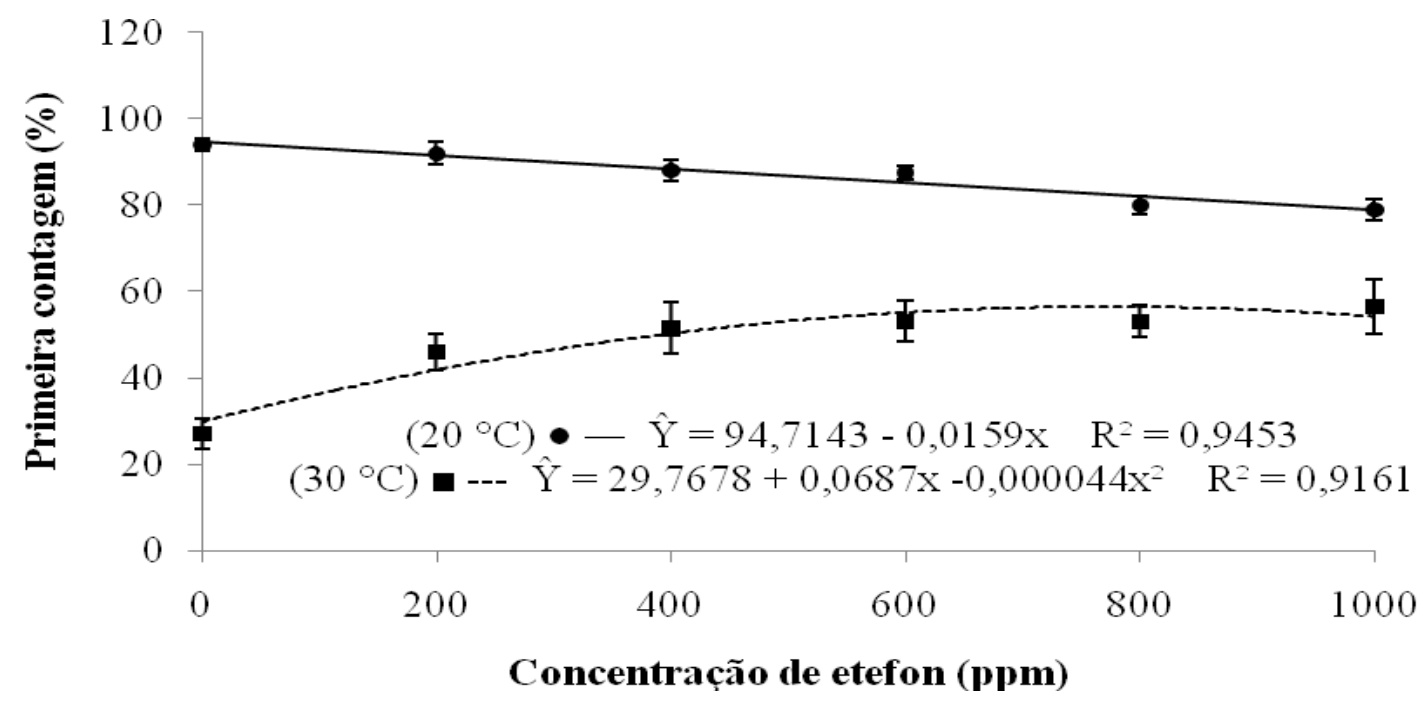

Figura 3. Primeira contagem da germinação de sementes de alface submetidas a diferentes temperaturas em função da concentração de etefon. First germination count of lettuce seeds submitted to different temperatures as a function of ethephon concentration.

Fonte: Autoria própria. Own authorship.

Houve interação significativa $(\mathrm{P}<0,05)$ entre os fatores estudados para o índice de velocidade de germinação (Figura 4), o qual apresentou comportamento semelhante à germinação (Figura 1) e primeira contagem de germinação (Figura 3), de modo que sementes postas para germinar na temperatura de $20^{\circ} \mathrm{C}$ tiveram reduções nos valores com o aumento da concentração de etefon. O valor de IVG obtido pelo tratamento controle ( $0 \mathrm{ppm}$ ) foi de 45,8, ao passo que a maior concentração promoveu um índece equivalente a 40,4, correspondendo a uma redução de $11,9 \%$.

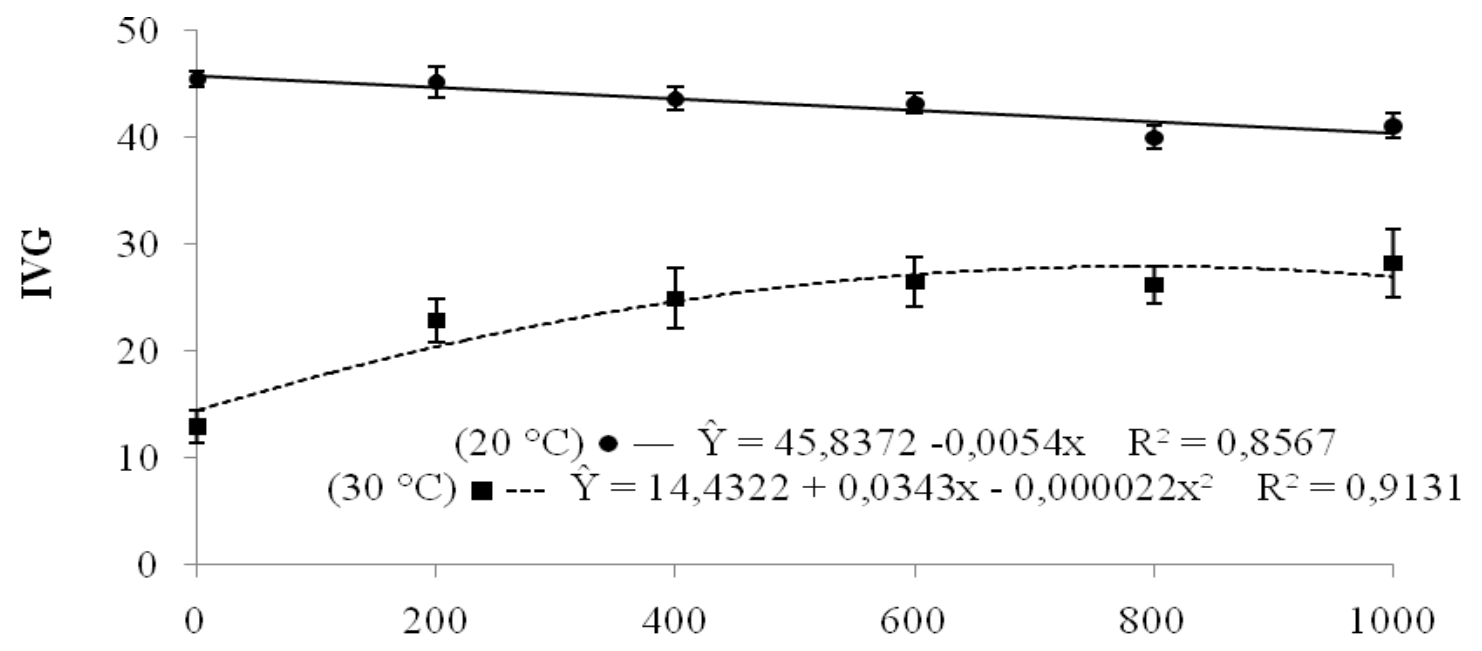

Concentração de etefon (ppm)

Figura 4. Índice de velocidade de germinação (IVG) de sementes de alface submetidas a diferentes temperaturas em função da concentração de etefon. Germination speed index (GSI) of lettuce seeds submitted to different temperatures as a function of ethephon concentration. Fonte: Autoria própria. Own authorship. 
Para a temperatura de $30^{\circ} \mathrm{C}$ o IVG progrediu proporcionalmente até a concentração de 780 ppm, na qual alcançou o maior índice $(27,8)$ (Figura 4). Maiores índices indicam que as sementes germinaram mais rapidamente e de maneira uniforme, sendo assim, consideradas mais vigorosas (DONATO et al., 2015). De acordo com Munizzi et al. (2010), sementes com maior potencial fisiológico (germinação e vigor) apresentam maior velocidade nos processos metabólicos, o que possibilita germinação mais rápida e uniforme, refletindo em um adequado estabelecimento de plântulas.

Tabela 1. Germinação, protrusão radicular, primeira contagem e índice de velocidade de germinação (IVG) de sementes de alface submetidas a diferentes concentrações de etefon em função da temperatura. Germination, root protrusion, first count and germination speed index (GSI) of lettuce seeds submitted to different concentrations of ethephon as a function of temperature.

\begin{tabular}{|c|c|c|c|c|c|c|}
\hline \multirow{2}{*}{$\begin{array}{c}\text { Temperatura } \\
\left({ }^{\circ} \mathrm{C}\right)\end{array}$} & \multicolumn{6}{|c|}{ Concentração de etefon (ppm) } \\
\hline & 0 & 200 & 400 & 600 & 800 & 1000 \\
\hline \multicolumn{7}{|c|}{ Germinação (\%) } \\
\hline 20 & $94 \mathrm{~A}$ & $92 \mathrm{~A}$ & $88 \mathrm{~A}$ & $88 \mathrm{~A}$ & $80 \mathrm{~A}$ & $83 \mathrm{~A}$ \\
\hline 30 & $30 \mathrm{~B}$ & $47 \mathrm{~B}$ & $52 \mathrm{~B}$ & $53 \mathrm{~B}$ & $53 \mathrm{~B}$ & $57 \mathrm{~B}$ \\
\hline $\mathrm{CV}(\%)$ & \multicolumn{6}{|c|}{11,00} \\
\hline \multicolumn{7}{|c|}{ Protrusão radicular $(\%)$} \\
\hline 20 & $90 \mathrm{~A}$ & $90 \mathrm{~A}$ & $90 \mathrm{~A}$ & $89 \mathrm{~A}$ & $91 \mathrm{~A}$ & $89 \mathrm{~A}$ \\
\hline 30 & $25 \mathrm{~B}$ & $55 \mathrm{~B}$ & $66 \mathrm{~B}$ & $74 \mathrm{~B}$ & $89 \mathrm{~A}$ & $69 \mathrm{~B}$ \\
\hline $\mathrm{CV}(\%)$ & \multicolumn{6}{|c|}{7,70} \\
\hline \multicolumn{7}{|c|}{ Primeira contagem $(\%)$} \\
\hline 20 & $94 \mathrm{~A}$ & $92 \mathrm{~A}$ & $88 \mathrm{~A}$ & $88 \mathrm{~A}$ & $80 \mathrm{~A}$ & $79 \mathrm{~A}$ \\
\hline 30 & $27 \mathrm{~B}$ & $46 \mathrm{~B}$ & $52 \mathrm{~B}$ & $53 \mathrm{~B}$ & $53 \mathrm{~B}$ & $57 \mathrm{~B}$ \\
\hline $\mathrm{CV}(\%)$ & \multicolumn{6}{|c|}{11,17} \\
\hline \multicolumn{7}{|c|}{ IVG } \\
\hline 20 & $45,5 \mathrm{~A}$ & $45,3 \mathrm{~A}$ & $43,6 \mathrm{~A}$ & $43,2 \mathrm{~A}$ & $40,0 \mathrm{~A}$ & $41,1 \mathrm{~A}$ \\
\hline 30 & $13,0 \mathrm{~B}$ & $22,9 \mathrm{~B}$ & $24,9 \mathrm{~B}$ & $26,5 \mathrm{~B}$ & $26,3 \mathrm{~B}$ & $28,3 \mathrm{~B}$ \\
\hline $\mathrm{CV}(\%)$ & \multicolumn{6}{|c|}{11,05} \\
\hline
\end{tabular}

Nota: Médias seguidas de mesma letra na coluna não diferem entre si pelo teste de Tukey a 5\% de probabilidade. Means followed by the same letter in the column do not differ by the Tukey test at 5\% probability.

Fonte: Autoria própria. Own authorship.

Analisando o desdobramento das temperaturas dentro de cada concentração estudada (Tabela 1), verificou-se que a temperatura de $20^{\circ} \mathrm{C}$ proporcionou maiores percentuais de germinação, protrusão radicular, primeira contagem e índice de velocidade de germinação. $\mathrm{O}$ efeito redutor sob altas temperaturas, provavelmente está relacionado com a rigidez do endosperma em condições de temperaturas elevadas, que atua como uma barreira física à protrusão da radícula, havendo a necessidade do amolecimento do mesmo para ocorrência da protrusão radicular. Essa função é exercida por enzimas da parede celular como a endo- $\beta$ mananase, que está presente no endosperma em diferentes isoformas (SILVA et al., 2004), 
nas quais são sugeridas como sendo reguladas pelo etileno (NASCIMENTO; CANTLIFFE, 2002).

Esses resultados corroboram com a análise de Nascimento, Croda e Lopes (2012), em que sementes de alface submetidas a altas temperaturas no período de embebição podem sofrer inibição temporária (termoinibição) ou total da germinação (termodormência), em função do endurecimento do endosperma.

A temperatura exerce forte influência na germinação, sendo considerada ótima a temperatura na qual a semente expressa seu potencial máximo de germinação no menor espaço de tempo (CARVALHO; NAKAGAWA, 2012).

Sabe-se que alta qualidade fisiológica (máxima germinação e vigor) é uma condição necessária para promover um adequado estabelecimento de plântulas. Assim, sementes mais vigorosas têm maior potencial de apresentar alto nível de desempenho mesmo sob condições ambientais adversas (MARCOS-FILHO, 2015).

No geral, os testes de germinação e vigor (protrusão de radícula, primeira contagem de germinação e IVG) em sementes de alface expressaram os melhores resultados na temperatura recomendada $\left(20^{\circ} \mathrm{C}\right)$ e não apresentaram efeitos positivos com o precursor de etileno. Contudo, sementes submetidas à germinação sob a temperatura de $30^{\circ} \mathrm{C}$ mostraram-se termoinibidas, com valores reduzidos para germinação e vigor. Apesar disso, com a aplicação exógena do precursor (etefon), os efeitos negativos da temperatura foram minimizados, com resultados crescentes e satisfatórios até atingirem concentrações entre 700 e 800 ppm.

\section{CONCLUSÕES}

A temperatura de $20^{\circ} \mathrm{C}$ é adequada para a germinação de sementes de alface e não apresenta efeito positivo com a aplicação exógena de etefon.

Em $30^{\circ} \mathrm{C}$ ocorre redução na qualidade de sementes, a qual é favorecida com o etefon, e as concentrações entre 726 e 786 ppm proporcionam melhores respostas no desempenho germinativo das sementes.

\section{AGRADECIMENTOS}

À Coordenação de Aperfeiçoamento de Pessoal de Nível superior (Capes) - Código de Financiamento 001, à Fundação de Amparo a Pesquisa do Estado de Minas Gerais (Fapemig), ao Conselho Nacional de Desenvolvimento Científico e Tecnológico (CNPq), pelo apoio financeiro e concessão de bolsas de estudo e à Universidade Estadual de Montes Claros (Unimontes), pela possibilidade de realização da pesquisa.

\section{REFERÊNCIAS BIBLIOGRÁFICAS}

ABUD, H. F.; ARAÚJO, E. F.; ARAúJO, R. F.; ARAÚJO, A. V.; PINTO, C. M. F. Qualidade fisiológica de sementes das pimentas malagueta e biquinho durante a ontogênese. Pesquisa Agropecuária Brasileira, Brasília, v. 48, n. 12, p.1546-1554, 2013. Disponível em: 
https://www.scielo.br/pdf/pab/v48n12/v48n12a03.pdf. Acesso em: 20 jul. 2020.

ALMEIDA, F. A. Qualidade fisiológica de sementes de cultivares de alface sob diferentes temperaturas na germinação. 2016. 42 f. Dissertação (Mestrado em Agricultura e Biodiversidade) - Universidade Federal de Sergipe, São Cristóvão, 2016.

BRASIL. Ministério da Agricultura, Pecuária e Abastecimento. Portaria $n^{\circ} 111$, de 04 de setembro de 2012. Padrões de identidade e qualidade para a produção e a comercialização de sementes de espécies olerícolas, condimentares, medicinais e aromáticas. Diário Oficial da União, Brasília, DF, 05 set. 2012. Seção 1, p. 3.

BRASIL. Ministério da Agricultura, Pecuária e Abastecimento. Regras para análise de sementes. Brasília: Secretaria de Defesa Agropecuária, 2009. 399 p.

CARVALHO, N. M.; NAKAGAWA, J. Sementes: ciência, tecnologia e produção. 5. ed. Jaboticabal: FUNEP, 2012. 590 p.

COSTA, C. J. Deterioração e armazenamento de sementes de hortaliças. 1. ed. Pelotas: Embrapa Clima Temperado, 2012. 30 p. Disponível em: https://www.infoteca.cnptia.embrapa.br/bitstream/doc/1005289/1/Documento355web.pdf. Acesso em: 06 ago. 2019.

DONATO, L. M. S.; RABELO, M. M.; DAVID, A. M. S. S.; ROCHA, A. F.; ROCHA, A. S.; BORGES, G. A. Qualidade fisiológica de sementes de melão em função do estádio de maturação dos frutos. Comunicata Scientiae, Bom Jesus, v. 6, n. 1, p.49-56, 2015. Disponível em: https://comunicatascientiae.com.br/comunicata/article/view/544/302. Acesso em: 08 jul. 2020.

FARIA, T. C. Desempenho de bioestimulantes e sua viabilidade econômica na cultura da soja. 2017. 62 f. Dissertação (Mestrado em Agronomia) - Universidade Federal de Goiás, Goiânia, 2017.

FERREIRA, D. F. Sisvar: a computer statistical analysis system. Ciência e Agrotecnologia, Lavras, v. 35, n. 6, p.1039-1042, 2011. Disponível em: http://www.scielo.br/scielo.php?script=sci_arttext\&pid=S1413-70542011000600001. Acesso em: 15 set. 2019.

IGLESIAS-FERNÁNDEZ, R.; MATILLA, A. J. Genes involved in ethylene and gibberellins metabolism are required for endosperm-limited germination of Sisymbrium offcinale L. seeds. Planta, Berlin, v. 231, n. 3, p.653-664, 2010. Disponível em: https://link.springer.com/article/10.1007/s00425-009-1073-5. Acesso em: 10 jul. 2020.

IGLESIAS-FERNÁNDEZ, R.; RODRÍGUEZ-GACIO, M. C.; BARRERO-SICILIA, C.; CARBONERO, P.; MATILLA, A. Three endo-ß-mannanase genes expresed in the micropylar endosperm and in the radicle influence germination of Arabidopsis thaliana seeds. Planta, Berlin, v. 233, n. 1, p.25-36, 2010. Disponível em: https://link.springer.com/article/10.1007\%2Fs00425-010-1257-z. Acesso em: 10 jul. 2020.

MAGUIRE, J. D. Speed of germination: aid in selection and evaluation for seedling emergence and vigour. Crop Science, Madson, v. 2, n. 2, p.176-177, 1962. Disponível em: https://acsess.onlinelibrary.wiley.com/doi/abs/10.2135/cropsci1962.0011183X000200020033 
x. Acesso em: 10 jul. 2020.

MARCOS-FILHO, J. Fisiologia de sementes de plantas cultivadas. 2. ed. Londrina: Abrates, 2015. 659 p.

MUNIZZI, A.; BRACCINI, A. L.; RANGEL, M. A. S.; SCAPIM, C. A.; ALBRECHT, L. P. Qualidade de sementes de quatro cultivares de soja, colhidas em dois locais no estado de Mato Grosso do Sul. Revista Brasileira de Sementes, Londrina, v. 32, n. 1, p.176-185, 2010. Disponível em: https://www.scielo.br/scielo.php?script=sci_arttext\&pid=S010131222010000100020\&lng=pt\&tlng=pt. Acesso em: 08 jul. 2020.

NASCIMENTO, W. M; CANTLIFFE, D. J. Germinação de sementes de alface sob altas temperaturas. Horticultura Brasileira, Brasília, v. 20, n. 1, p.103-106, 2002. Disponível em: http://www.scielo.br/pdf/hb/v20n1/14427.pdf. Acesso em: 02 jul. 2019.

NASCIMENTO, W. M.; CRODA, M. D.; LOPES, A. C. A. Produção de sementes, qualidade fisiológica e identificação de genótipos de alface termotolerantes. Revista Brasileira de Sementes, Londrina, v. 34, n. 3, p.510-517, 2012. Disponível em: http://www.scielo.br/pdf/rbs/v34n3/20.pdf. Acesso em: 02 jul. 2019.

NASCIMENTO, W. M. Germinação de sementes de alface. Brasília: Embrapa Hortaliças, 2002. 10 p. (Circular Técnica, 29).

NASCIMENTO, W. M.; PEREIRA, R. S. Testes para avaliação do potencial fisiológico de sementes de alface e sua relação com a germinação sob temperaturas adversas. Revista Brasileira de Sementes, Londrina, v. 29, n. 3, p.175-179, 2007. Disponível em: http://www.scielo.br/pdf/rbs/v29n3/a21v29n3.pdf. Acesso em 24 ago. 2019.

PEREIRA, F. R. S.; BRACHTVOGEL, E. L.; CRUZ, S. C. S.; BICUDO, S. J.; MACHADO, C. G.; PEREIRA, J. C. Qualidade fisiológica de sementes de milho tratadas com molibdênio. Revista Brasileira de Sementes, Londrina, v. 34, n. 3, p.450-456, 2012. Disponível em: https://www.scielo.br/pdf/rbs/v34n3/12.pdf. Acesso em: 18 jul. 2020.

RODRIGUES, D. L.; LOPES, H. M.; SILVA, E. R.; MENEZES, B. R. S. Embebição, condicionamento fisiológico e efeito do hipoclorito de sódio na germinação de sementes de alface. Revista Trópica, Chapadinha, v. 6, n. 1, p.52-61, 2012. Disponível em: http://www.periodicoseletronicos.ufma.br/index.php/ccaatropica/article/view/373. Acesso em 18 jul. 2020.

SALA, F. C.; COSTA, C. P. Retrospectiva e tendência da alfacicultura brasileira. Horticultura Brasileira, Vitória da Conquista, v. 30, n. 2, p.187-194, 2012. Disponível em: http://www.scielo.br/pdf/hb/v30n2/v30n2a02.pdf. Acesso em: 02 set. 2019.

SILVA, E. A. A.; TOOROP, P. E.; VAN AELST, A. C.; HILHORST, H. W. Abscisic acid controls embryo growth potential and endosperm cap weakening during coffee (Coffea arabica cv. Rubi) seed germination. Planta, Berlin, v. 220, n. 2, p.251-261, 2004. Disponível em: https://link.springer.com/article/10.1007/s00425-004-1344-0. Acesso em: 15 set. 2019.

VILLELA, R. R. Influência da temperatura na produção e qualidade fisiológica de sementes de alface. 2009. 81 f. Tese (Doutorado em Produção Vegetal) - Universidade Federal de Lavras, Lavras, 2009. 